\title{
Design Mix Formulation and Optimization of Metakaolin Based Alkali Activated Geopolymer Concrete with the Taguchi Method
}

\author{
Okovido J. O. ${ }^{1}$ and Yahya I. A. ${ }^{2}$ \\ ${ }^{1}$ Department of Civil/Structural Engineering, Faculty of Engineering, University of Benin, Benin City, Nigeria \\ ${ }^{2}$ Department of Civil Engineering, School of Engineering and Engineering Technology, Moddibo Adama \\ University of Technology, Yola, Adamawa State, Nigeria \\ Corresponding Author: ${ }^{2}$ ismakola2012@gmail.com
}

https://doi.org/10.36263/nijest.2021.01.0249

\begin{abstract}
Concrete mix formulation is the science of deciding relative proportions of ingredients of concrete, to achieve desired properties in the most economical way. Formulation of concrete mix requires adequate knowledge of the properties of its constituents. Aluminosilicate materials have recently found applications in construction industry due to their unique and flexible properties. The metakaolin used for this study was the locally sourced kaolin calcined at $750^{\circ} \mathrm{C}$. The alkali activating reagents include a fixed concentration of sodium silicate solution and sodium hydroxide solutions of three different concentrations. Strength development of metakaolin - based geopolymer concrete is quite different from that of ordinary Portland cement concrete due to differences in their constituents, hence, the need for special formulation, most especially when high strength is required. Taguchi method was adopted in this study to formulate mix proportion for high compressive strength of geopolymer concrete at ambient curing condition. Four parameters were selected that are more likely to influence the compressive strength of metakaolin - based geopolymer concrete, these include aggregate content, alkali - binder ratio, alkali reagent ratio and alkali reagent concentration. The effect of these parameters on the density, workability and compressive strength at 3, 7 and 28 days are determined. The result showed that an optimum mix obtained from a formulation formula $\left(2.75 \mathrm{SiO}_{2} * \mathrm{Al}_{2} \mathrm{O}_{3} * 0.55 \mathrm{Na}_{2} \mathrm{O} * 6.8 \mathrm{H}_{2} \mathrm{O}\right)$ produced a compressive strength of $62 \mathrm{MPa}$ at 28 days of open air curing. It was revealed that the molar concentration of the alkali reagent (sodium hydroxide) should be kept within 10M range for an open air curing, the alkali reagents to binder ratio should be kept at 0.7 or less with no addition of water to achieve reasonable workability. Also, it has been observed that the bulk density of metakaolin - based geopolymer concrete that yielded substantial strength fall within $2250 \mathrm{~kg} / \mathrm{m}^{3}$ and $2350 \mathrm{~kg} / \mathrm{m}^{3}$.
\end{abstract}

Keywords: Aluminosilicate Material, Geopolymer Concrete, Taguchi Method, Mix Formulation, Mix Optimization

\subsection{Introduction}

Concrete is a global construction material that has impacted the environment more than any other construction material, because it can be produced under a plethora of innovative technology, material and conditions. According to Ikponmwosa et al., (2014), the fact that concrete allows innovations and creativity in its production, either by altering its composition during mix designs, or by the addition of chemical admixtures or mineral additives etc., has led to the development of many types of concrete with different properties and for different applications. One of such type of concrete is metakaolin based alkali - activated geopolymer concrete, a construction material that is yet to be developed in Nigeria despite the abundance deposit of kaolin in the country.

Geopolymers are solid materials that can be synthesised by the reaction of an aluminosilicate powder with an alkaline solution (Pouhet, 2016). Theoretically, any material containing aluminium and silicon can be a solid source of aluminosilicate for geopolymerization (Ahmed Al - Dujaili et al., 2020). However, past studies have shown that the most often used materials are blast furnace slags, fly ash 
and calcined clay. The most common clay is the kaolin which upon thermal activation within temperature range of $650^{\circ} \mathrm{C}$ to $800^{\circ} \mathrm{C}$ becomes metakaolin (Pera, 2001). Metakaolin - based geopolymer is said to be purer and can be readily characterised hence, they are referred to as model system without the complexities associated with other aluminosilicate source such as fly ash (Shihab et al., 2018).

The activating reagent is an aqueous form of alkaline compound. The common used compounds are hydroxides $\left(\mathrm{Na}^{+}\right.$and $\left.\mathrm{K}^{+}\right)$, silicates $\left(\mathrm{Na}^{+}\right.$and $\left.\mathrm{K}^{+}\right)$and silica gel (Ahmed $\mathrm{Al}$ - Dujaili et al., 2020). The silicate solution increases the $\mathrm{SiO}_{2}$ content in the mix while the hydroxide solution increases the level of alkalinity of the mix. The origin of the element composing the geopolymer mixture is as shown in Figure 1. The reaction mechanism of geopolymer is a chemical process that involves the transformation of vitreous structures into a stable and compact composite. This chemical process only takes place in alkaline environment which help to dissolve the silica and alumina in the solid material.

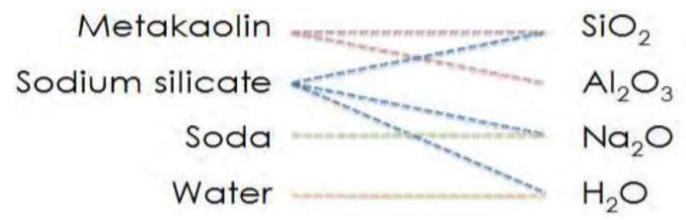

Figure 1: Origin of the element composing the geopolymer (Pouhet, 2016)

The properties of geopolymer depend on crystallographic and microstructural features of the alkali activated product which are directly affected by the mix formulation of the individual element that composed the geopolymer. Mix formulation of metakaolin - based alkali - activated geopolymer concrete is predicated upon four compounds (i.e. $\mathrm{SiO}_{2}, \mathrm{Al}_{2} \mathrm{O}_{3}, \mathrm{Na}_{2} \mathrm{O}$ and $\mathrm{H}_{2} \mathrm{O}$ ). The metakaolin powder provides silica and aluminium with a fixed $\mathrm{SiO}_{2} / \mathrm{Al}_{2} \mathrm{O}_{3}$ ratio. The sodium silicate solution contributes silica, sodium and water in fixed proportions. The sodium hydroxide in different molar concentration allows for $\mathrm{Na}_{2} \mathrm{O}$ and $\mathrm{H}_{2} \mathrm{O}$ to vary in each mix formulation.

The composition ranges of alkaline/binder, $\mathrm{SiO}_{2} / \mathrm{Al}_{2} \mathrm{O}_{3}, \mathrm{Na}_{2} \mathrm{O} / \mathrm{Al}_{2} \mathrm{O}_{3}, \mathrm{H}_{2} \mathrm{O} / \mathrm{Na}_{2} \mathrm{O}$ ratios of the component materials can be used to formulate the right mix for alkaline - activated products. These composition ranges are determined by such parameters as aggregate content, alkali reagent ratio, alkali/binder ratio and alkali concentration. However, the measure of successes or failures of every mix formulation can be based on the compressive strength properties of the geopolymer products (Hardjito et al., 2004; Fernandez - Jimenez et al., 2006; Shindunata et al., 2006).

Studying the effects of these parameters on the strength properties of geopolymer concrete by the full factorial design tends to be too cumbersome to yield efficient results. To overcome this problem, suitable methods of design of experiment, such as Taguchi method was used to ascertain the effect of four parameters on the compressive strength property of metakaolin - based geopolymer concrete. Taguchi and Konishi (1987) developed Taguchi method as a statistical method for conducting minimal number of experiment with potential of giving full information of all factors that determine the performance properties of the product. Taguchi method is a design of experiment (DOE) approach which seek to develop products and processes that are robust to environmental factors and other sources of variation (Montgomery, 2013). Taguchi method helps reduce time and cost on testing all possible combinations by using one factor at a time to fulfil Full Factorial Experiment (FFE) (Olivia, 2011).

Taguchi optimization method has been used by researchers in different areas such as the optimization of blended cements (Wu and Naik, 2003), the optimization of mineral admixture and assessment of mix proportion for self - compacting concrete (Ozbay et al., 2009), and recently for the optimization of the properties of metakaolin based geopolymer pastes (Ahmed Al - Dujaili et al., 2020), and to determine the proportion of materials with optimal replacement of cement for optimum compressive strength properties of mortar (De Side et al., 2020). However, at present there is no study in relation to the use of Taguchi method to establish a mix formulation for high strength metakaolin - based geopolymer concrete. This study therefore aims to determine the right mix formulation for metakaolin - based geopolymer concrete with high compressive strength as a prerequisite for further investigation into other important properties of geopolymer concrete. 


\subsection{Materials and Methods}

\subsection{Metakaolin}

It was decided that the materials for this study must be locally sourced. Ten bags of powder kaolin were supplied by local supplier from Ikpeshi in Edo State. The raw kaolin was pinkish white in colour. The calcination process of the kaolin took place in the Structural laboratory at University of Benin, with a portable electric furnace presented in Figure 2. The calcination process involved filling of a metal container with kaolin and placed in the furnace where it is heated up to $750{ }^{\circ} \mathrm{C}$ over a period of $4 \mathrm{hrs}$. Then the hot material is left in the oven to cool till the next day.

The raw kaolin has a dull pinkish colour and the metakaolin turned out to be smooth pinkish white colour after calcination. A sample of the metakaolin was taken for analysis of its oxide composition by $\mathrm{x}$ - ray fluorescence (XRF) analysis and the result is as presented in Table 1.

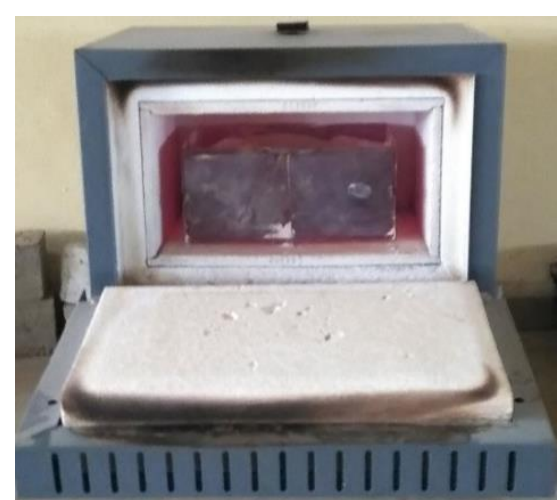

Figure 2: Calcination process of kaolin

Table 1: Chemical composition of metakaolin

\begin{tabular}{lllllllllll}
\hline Comp. (\%) & $\mathrm{SiO}_{2}$ & $\mathrm{Al}_{2} \mathrm{O}_{3}$ & $\mathrm{Fe}_{2} \mathrm{O}_{3}$ & $\mathrm{CaO}$ & $\mathrm{MgO}$ & $\mathrm{Na}_{2} \mathrm{O}$ & $\mathrm{K}_{2} \mathrm{O}$ & $\mathrm{P}_{2} \mathrm{O}_{5}$ & $\mathrm{TiO}_{2}$ & LOI \\
\hline MK (\%) & 49.10 & 37.93 & 0.38 & 0.34 & 0.11 & 0.28 & 1.32 & 0.12 & 1.14 & 1.03 \\
\hline
\end{tabular}

\subsection{Alkaline solution}

The alkaline activators are the sodium silicate solution and sodium hydroxide solution at specific molarity.

The $\mathrm{NaOH}$ flake of $99 \%$ purity grade was obtained from a local supplier at Onitsha market. Sodium hydroxide solutions were prepared in three molar concentrations (10M, 12M and $15 \mathrm{M})$. For a typical $15 \mathrm{M}$ concentration, $600 \mathrm{~g}$ of sodium hydroxide flakes was dissolved in 1 litre of distilled water to make a $15 \mathrm{M}$ solution. The preparation of sodium hydroxide solution took place 24 hours before use, to ensure that the generated heat during preparation was completely dissipated.

The sodium silicate solution used has a modulus silicate (Ms) of 2.0 and was obtained from a local supplier with chemical characteristics as presented in Table 2.

Table 2: Chemical characteristics of sodium silicate

\begin{tabular}{lllllll}
\hline Prop. & $\mathrm{SiO}_{2}(\%)$ & $\mathrm{Na}_{2} \mathrm{O}(\%)$ & $\mathrm{SiO}_{2} / \mathrm{Na}_{2} \mathrm{O}$ & $\mathrm{H}_{2} \mathrm{O}(\%)$ & $\mathrm{pH}$ & Density $\left(\mathrm{g} / \mathrm{cm}^{3}\right)$ \\
\hline Value & 29.4 & 14.7 & 2.0 & 55.9 & 12.6 & 1.35 \\
\hline
\end{tabular}

\subsection{Aggregates}

Coarse aggregates for this study were crushed granite obtained from local supplier. The particle sizes that passed through $10 \mathrm{~mm}$ sieve were used for this study. The fine aggregates used were the natural sand obtained from local supplier and the maximum nominal size of $1.18 \mathrm{~mm}$ was used throughout the project. The aggregates were treated with little amount of water a day before mixing to ensure that they are dust - free and to achieve saturated surface dry condition. 


\subsection{Water}

Deionize/distilled water was used during the course of this study so as to ensure minimal chloride ions content so as to reduce chloride - induced corrosion. Water was used for preparation of sodium hydroxide solution, since the sodium silicate was obtained in liquid form. No addition of water in the mix for geopolymer concrete, except the water in the activating solutions, because of the open air curing method adopted in this study.

\subsection{Mix formulation by Taguchi method}

The four parameters with direct effects on the compressive strength of geopolymer concrete are selected as presented in table 3. The aggregate content in percentage of the total mass of concrete is considered most critical factor (Factor A), the alkali activator - binder ratio (factor B), then sodium silicate - sodium hydroxide ratio (factor $\mathrm{C}$ ) and finally sodium hydroxide molarity (factor D). Each of these factors is considered under three trial levels to ascertain their influence on the strength development of metakaolin - based geopolymer concrete.

Table 3: Parameters and level of trials

\begin{tabular}{lllll}
\hline Parameter & Factors/Levels & 1 & 2 & 3 \\
\hline Aggregate Percent & $\mathrm{A}$ & 60 & 65 & 70 \\
A/B ratio & $\mathrm{B}$ & 0.70 & 0.75 & 0.80 \\
SS/SH ratio & $\mathrm{C}$ & 1.5 & 2.0 & 2.5 \\
SH Molarity & $\mathrm{D}$ & $10 \mathrm{M}$ & $12 \mathrm{M}$ & $15 \mathrm{M}$ \\
\hline
\end{tabular}

The parameters were distributed using Taguchi's orthogonal array method for $\left(3^{4}\right)$ mix trials to produce nine trial mixes as shown in Table 4 . The orthogonal array distribution produced the mix proportion presented in Table 5.

Table 4: Taguchi's orthogonal arrays method of distribution of factors and levels

\begin{tabular}{llllllllll}
\hline Factor/Mix Trial & T1 & T2 & T3 & T4 & T5 & T6 & T7 & T8 \\
\hline A & 1 & 1 & 1 & 2 & 2 & 2 & 3 & 3 \\
B & 1 & 2 & 3 & 1 & 2 & 3 & 1 & 2 \\
C & 1 & 2 & 3 & 2 & 3 & 1 & 3 & 1 \\
D & 1 & 2 & 3 & 3 & 1 & 2 & 2 & 3 \\
\hline
\end{tabular}

Table 5: Summary of mix formulation for metakaolin-based geopolymer concrete

\begin{tabular}{|c|c|c|c|c|c|c|c|c|c|}
\hline$\left(\mathrm{kg} / \mathrm{m}^{3}\right)$ & $\mathrm{T} 1$ & $\mathrm{~T} 2$ & T3 & $\mathrm{T} 4$ & T5 & T6 & $\mathrm{T} 7$ & T8 & T9 \\
\hline MK750 & 565 & 549 & 533 & 494 & 480 & 467 & 424 & 411 & 400 \\
\hline Fine Agg. & 720 & 720 & 720 & 780 & 780 & 780 & 840 & 840 & 840 \\
\hline Coarse Agg. & 720 & 720 & 720 & 780 & 780 & 780 & 840 & 840 & 840 \\
\hline SS sol. & 237 & 274 & 305 & 231 & 257 & 224 & 211 & 185 & 213 \\
\hline SH Sol. & 158 & 137 & 122 & 115 & 103 & 149 & 85 & 124 & 107 \\
\hline $\mathrm{A} / \mathrm{B}$ & 0.70 & 0.75 & 0.80 & 0.70 & 0.75 & 0.80 & 0.70 & 0.75 & 0.80 \\
\hline SH Mol. & $10 \mathrm{M}$ & $12 \mathrm{M}$ & $15 \mathrm{M}$ & $15 \mathrm{M}$ & $10 \mathrm{M}$ & $12 \mathrm{M}$ & $12 \mathrm{M}$ & $15 \mathrm{M}$ & $10 \mathrm{M}$ \\
\hline $\mathrm{SS} / \mathrm{SH}$ & 1.5 & 2.0 & 2.5 & 2.0 & 2.5 & 1.5 & 2.5 & 1.5 & 2.0 \\
\hline Agg. (\%) & 60 & 60 & 60 & 65 & 65 & 65 & 70 & 70 & 70 \\
\hline $\mathrm{MK}(\%)$ & 23.5 & 23 & 22 & 21 & 20 & 19.5 & 18 & 13 & 13 \\
\hline Alk. (\%) & 16.5 & 17 & 18 & 14 & 15 & 15.5 & 12 & 13 & 13 \\
\hline $\mathrm{SiO}_{2} / \mathrm{Na}_{2} \mathrm{O}$ & 5.00 & 4.74 & 4.42 & 4.98 & 5.18 & 4.24 & 5.21 & 4.42 & 4.76 \\
\hline $\mathrm{SiO}_{2} / \mathrm{Al}_{2} \mathrm{O}_{3}$ & 2.75 & 2.86 & 2.95 & 2.81 & 2.90 & 2.83 & 2.85 & 2.79 & 2.90 \\
\hline $\mathrm{Na}_{2} \mathrm{O} / \mathrm{Al}_{2} \mathrm{O}_{3}$ & 0.55 & 0.60 & 0.67 & 0.57 & 0.56 & 0.67 & 0.55 & 0.63 & 0.61 \\
\hline $\mathrm{H}_{2} \mathrm{O} / \mathrm{Na}_{2} \mathrm{O}$ & 12.30 & 11.54 & 10.81 & 11.20 & 12.42 & 11.37 & 11.66 & 10.97 & 12.40 \\
\hline
\end{tabular}

\subsection{Concrete casting and curing}

The metakaolin - based geopolymer concrete specimens were prepared by mixing a measured dry aggregate with a measured metakaolin powder before the addition of alkaline solutions, which are separately prepared. The combined materials were thoroughly mixed until homogenous mixture was obtained. The fresh mixture was placed in slump cone for workability determination according to EN206 - 1. Low slump class S2 was observed in the concrete having $70 \%$ by mass of aggregate, despite the increase in alkaline/binder ratio from 0.7 to 0.8. Moderate slump class S3 was observed in the concrete having $65 \%$ by mass of aggregates. The $60 \%$ by mass of aggregates, showed a collapsed slump class S4 - S5. 
After the slump determination, the fresh concrete was re - mixed and placed in $100 \times 100 \times 100$ mould and compacted on vibratory table. The moulds were initially coated with releasing agent to prevent sticking to the mould. The specimens in the mould were covered with thick polythene sheet for the next 24 hours before they were demoulded and kept in open air for continuous curing until test days.

\subsection{Control specimen preparation}

The use of Portland cement concrete in this study was to serve as control specimen for the purpose of comparative analysis. Its mix design did not serve as a control mix for metakaolin - based geopolymer concrete because their mix procedure differs. OPC concrete mix design was done for three different aggregates content in comparison with geopolymer concrete of the same aggregate content. Table 6 shows the summary of mix proportioning for OPC concrete for three aggregate contents, which are represented as control trial (CT01, CT02 and CT03). The OPC concrete specimens were prepared following the same procedure as geopolymer with the use of water instead as the main activating agent and as curing medium after demoulding.

Table 6: Mix proportioning for Portland cement concrete

\begin{tabular}{|c|c|c|c|c|c|c|c|}
\hline \multirow[t]{2}{*}{ Mix No } & \multicolumn{7}{|c|}{ Concrete Mix $\left(\mathrm{kg} / \mathrm{m}^{3}\right)$} \\
\hline & Cement & F.A & C.A & Add. $\mathrm{H}_{2} \mathrm{O}$ & Agg. (\%) & $\mathrm{w} / \mathrm{c}$ ratio & Slump (mm) \\
\hline CT01 & 662 & 720 & 720 & 298 & 60 & 0.45 & 75 \\
\hline СТ02 & 579 & 780 & 780 & 261 & 65 & 0.45 & 60 \\
\hline СТ03 & 497 & 840 & 840 & 223 & 70 & 0.45 & 50 \\
\hline
\end{tabular}

\subsection{Results and Discussion}

\subsection{XRF analysis of metakaolin sample}

The result of the plot of the $\mathrm{x}$-ray fluorescence analysis of the metakaolin for this study is as presented in Figure 3. It is clearly seen that the major oxide constituent of the metakaolin are the silicon oxide and aluminium oxide both of which constitute $87 \%$ of the total chemical oxide of the sample. In view of the large percentage of $\mathrm{SiO}_{2}$ and $\mathrm{Al}_{2} \mathrm{O}_{3}$ in the metakaolin, most of the characteristics of the metakaolin as binder in geopolymer concrete are traceable to the interaction between these two major chemical oxides, and in essence they both determine the possible mix formulation for desired strength properties of metakaolin - based geopolymer concrete.

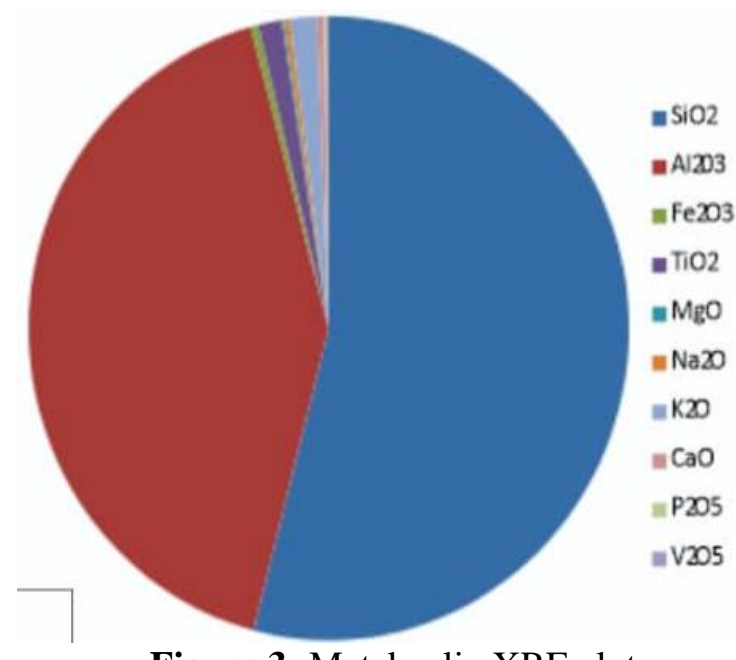

Figure 3: Metakaolin XRF plot

\subsection{Bulk density and workability of geopolymer concrete}

The workability of the geopolymer concrete as measured by slump value and the density of hardened concrete at three different test days are as presented in Table 7. It could be observed that the bulk density is influenced by the aggregate content in the geopolymer mix. The mix with $70 \%$ aggregate content has the highest range of bulk density, while there is insignificant difference in the mix with $65 \%$ and $60 \%$ aggregate content. This could be due to adequate amount of activated metakaolin in the mix for aggregate content of $65 \%$ and $60 \%$. The slump value obtained in this study can only be attributable to the alkali content since there is no additional water except the amount in the alkali 
solution. The slump value indicates the impact of the sodium silicate/sodium hydroxide ratio as the mix with the highest amount of sodium hydroxide of lowest concentration produced the highest slump value, and also exhibited the same property as the self - compacting concrete. This could be due to low viscosity of sodium hydroxide solution as compared with sodium silicate solution.

Table 7: Bulk density and slump value for metakaolin-based geopolymer concrete

\begin{tabular}{llllllllll}
\hline Mix & $\mathrm{T} 1$ & $\mathrm{~T} 2$ & $\mathrm{~T} 3$ & $\mathrm{~T} 4$ & $\mathrm{~T} 5$ & $\mathrm{~T} 6$ & $\mathrm{~T} 7$ & $\mathrm{~T} 8$ & $\mathrm{~T} 9$ \\
\hline $\begin{array}{l}3 \text { day density } \\
\left(\mathrm{kg} / \mathrm{m}^{3}\right)\end{array}$ & 2335 & 2400 & 2390 & 2250 & 2280 & 2300 & 2450 & 2465 & 2400 \\
$\begin{array}{l}7 \text { day density } \\
\left(\mathrm{kg} / \mathrm{m}^{3}\right)\end{array}$ & 2330 & 2350 & 2350 & 2250 & 2270 & 2285 & 2450 & 2430 & 2390 \\
$\begin{array}{l}28 \text { day density } \\
\left(\mathrm{kg} / \mathrm{m}^{3}\right)\end{array}$ & 2300 & 2395 & 2330 & 2200 & 2265 & 2285 & 2435 & 2470 & 2420 \\
Slump $(\mathrm{mm})$ & 205 & 195 & 190 & 155 & 150 & 135 & 75 & 75 & 60 \\
\hline
\end{tabular}

\subsection{Compressive strength of geopolymer concrete}

Compressive strength was used in the evaluation of mixes using the Taguchi method. As shown in Table 8, the compressive strength results of metakaolin - based geopolymer concrete was obtained as the average of three samples for each test. It was observed that the strength varies significantly between 1 and 7 days, due to rapid geopolymerization process, and there was insignificant change in strength between the 7 and 28 days of open air curing. The highest strength was recorded for trial mix $\mathrm{T} 1$ at 28 days with $62 \mathrm{MPa}$. The mix $\mathrm{T} 1$ contained the lowest $\mathrm{SiO}_{2} / \mathrm{Al}_{2} \mathrm{O}_{3}$ ratio and the highest metakaolin content in comparison with other mixes, hence the mix was favored by the low SS/SH ratio and $\mathrm{SH}$ molarity to keep the additional $\mathrm{SiO}_{2}$ from sodium silicate in check. In order to achieve the mix formulation for optimum strength it is required to control the $\mathrm{SiO}_{2} / \mathrm{Al}_{2} \mathrm{O}_{3}$ ratio using the activating solution, since the $\mathrm{SiO}_{2} / \mathrm{Al}_{2} \mathrm{O}_{3}$ of the metakaolin is already fixed. Also, it can be observed that mixes with $10 \mathrm{M}$ concentration of sodium hydroxide performed better in comparison with higher molarity. It can then be argued that the metakaolin used for this study requires low molar concentration of sodium hydroxide for activation, and this may be traced to its high $\mathrm{Al}_{2} \mathrm{O}_{3}$ content.

Table 8: Compressive strength of geopolymer and Portland cement concrete

\begin{tabular}{llllllllll}
\hline Comp. Str. (MPa) & T1 & T2 & T3 & T4 & T5 & T6 & T7 & T8 & T9 \\
\hline 3 day & 48 & 21 & 29 & 35 & 33 & 36 & 38 & 33 & 29 \\
7 day & 60 & 30 & 40 & 39 & 36 & 40 & 39 & 34 & 30 \\
28 day & 62 & 31 & 42 & 41 & 40 & 40 & 39 & 34 & 30 \\
\hline
\end{tabular}

The mechanical strength of geopolymer concrete is completely governed by the binding strength of alkali - activated metakaolin in the mix. The essence of seeking optimum mix proportioning is to ensure right amount of metakaolin for a given amount of aggregate and the sufficient amount of alkali - activator required for complete activation of the metakaolin for efficient binding property. In hundred percent metakaolin - based alkali - activated concrete, there is no strength to be gained where metakaolin serves as the mineral filler, due to insufficient amount of activator or as a result of excessive amount of metakaolin in the mix. The mix formulation equation 1 produced the maximum strength value and it is typical of metakaolin - based geopolymer concrete for ambient curing condition. The amount of water (both in the activating reagent and added water) required for desired workability may be varied depending on the type of curing and the nature of exposure condition.

$$
2.75 \mathrm{SiO}_{2} * \mathrm{Al}_{2} \mathrm{O}_{3} * 0.55 \mathrm{Na}_{2} \mathrm{O} * 6.8 \mathrm{H}_{2} \mathrm{O}
$$

From the mix design, the only water content in the mix is that with which the alkaline reagents were prepared, hence, with correct molarity of sodium hydroxide and adequate concentration of sodium silicate, no extra water is required to achieve significant strength of metakaolin - based geopolymer concrete. Excess amount of water in the mix, beyond the need of the alkaline activators would only fill and displace the void meant for activated paste for optimum binding effect on the aggregate, leading to weak concrete product.

The compressive strength results for OPC concrete are as presented in Table 9 for 7, 14 and 28 days of water curing. 
Table 9: Compressive strength of Portland cement concrete

\begin{tabular}{llll}
\hline Mix No & \multicolumn{2}{l}{ Compressive Strength (MPa) } \\
\cline { 2 - 4 } & 7 day & 14 day & 28 day \\
\hline CT01 & 38 & 45 & 49 \\
CT02 & 37 & 44 & 47 \\
CT03 & 32 & 38 & 42 \\
\hline
\end{tabular}

\subsubsection{Compressive strength analysis by Taguchi method}

In Taguchi method, Signal/Noise ratio analysis are carried out in order to study the response of experiment that combine repetitions and the effect of trial levels in one data point. Using the Signal/Noise ratio analysis in this study, a response index was established in the experiment. The average contribution of each level of a factor to the final strength was calculated by adding the strength of mixtures corresponding to each level and dividing the sum by the number of repetition for the level and the results are as shown in table $10-12$. The plots of compressive strength response index against the selected factors for the mix formulation are presented in Figure $4-6$.

Table 10 shows the results of Taguchi analysis for the 3 - day compressive strength of metakaolin based geopolymer concrete. The ranking of the result indicates that the most influential factors on the compressive strength is the alkali/binder (A/B) ratio. It shows that the selected factors keep their order of importance from $\mathrm{A} / \mathrm{B}$ ratio to $\mathrm{SH}$ molarity with the exception of aggregate content which indicate the least effect. Figure 4 shows the plot of the major effect for the compressive strength during 3 day of geopolymer concrete. The plot shows that the larger the signal - to - noise the better for each of the compressive strength results. It also indicates that factor $\mathrm{B}, \mathrm{C}$ and $\mathrm{D}$ tend to pick up positive momentum at level three while factor A shows a downturn which could be interpreted as a negative effect on the compressive strength development of geopolymer concrete.

Table 11 shows the results of 7-day compressive strength analyzed by Taguchi method for geopolymer concrete and the corresponding plot of the major effects is as presented in Figure 5. It can be seen that the alkali/binder (A/B) ratio has the major effect while the least impact on the 7 - day compressive strength of geopolymer concrete was recorded for molarity of sodium hydroxide as initially proposed. This indicates that the activated metakaolin is still binding on the aggregates in the mix as the concrete ages. The plot in Figure 5 shows clearly that the negative impact associated with increasing aggregate content persist at 7-day maturity of geopolymer concrete.

Table 12 presents the results for 28-day compressive strength as analyzed by Taguchi method. It could be seen that the same pattern of strength development as 7-day compression strength is maintained at 28 days. It shows that the alkali/binder (A/B) ratio remained the most affecting factor in the compressive strength of geopolymer concrete at 28 days. The corresponding plot of the major effects of the selected factors is presented in Figure 6. It could be seen from Figure 6 that the downward trend associated with increasing aggregate content in the mix persist at 28-day. The highest A/B ratio (0.8) yielded lowest 28-day strength, despite the fact that it gave highest 7 - day strength. This may be due to excess of alkali in the concrete matrix after active geopolymerization period, which cause weakness in the interface of aggregates. In general, it can be seen that the middle level for each of the selected factors except the aggregate content has the lowest impact on compressive strength as the geopolymer concrete ages.

Table 10: Response value for 3-day compressive strength of geopolymer concrete

\begin{tabular}{lllll}
\hline Level/Factors & $\mathrm{A}$ & $\mathrm{B}$ & $\mathrm{C}$ & $\mathrm{D}$ \\
\hline 1 & 32.7 & 40.3 & 39.0 & 36.7 \\
2 & 34.7 & 29.0 & 28.3 & 31.7 \\
3 & 33.3 & 31.3 & 33.3 & 32.3 \\
S. Deviation & 0.84 & 4.88 & 4.37 & 2.20 \\
Rank & 4 & 1 & 2 & 3 \\
\hline
\end{tabular}


A

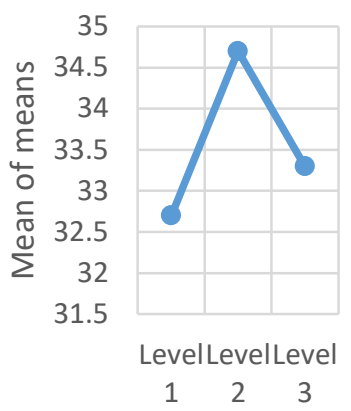

B

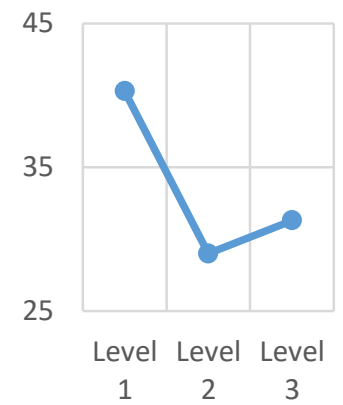

C

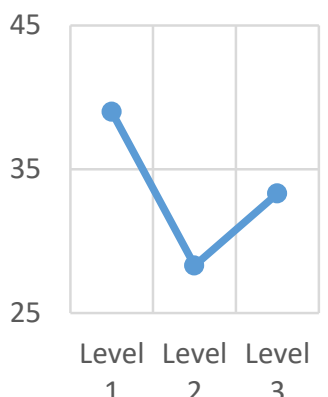

D

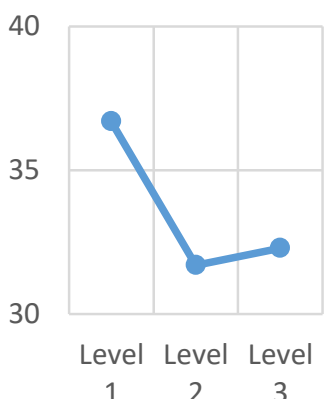

Figure 4: Major effect for the 3 - day compressive strength of geopolymer concrete

Table 11: Response value by Taguchi method for 7 - day compressive strength

\begin{tabular}{lllll}
\hline Level/Factors & $\mathrm{A}$ & $\mathrm{B}$ & $\mathrm{C}$ & $\mathrm{D}$ \\
\hline 1 & 43.3 & 46.0 & 44.7 & 42.0 \\
2 & 38.3 & 33.3 & 33.0 & 36.3 \\
3 & 34.3 & 36.7 & 38.3 & 37.7 \\
S. Deviation & 3.68 & 5.37 & 4.78 & 2.43 \\
Rank & 3 & 1 & 2 & 4 \\
\hline
\end{tabular}

A

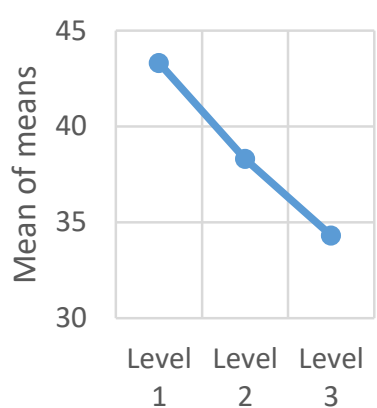

B

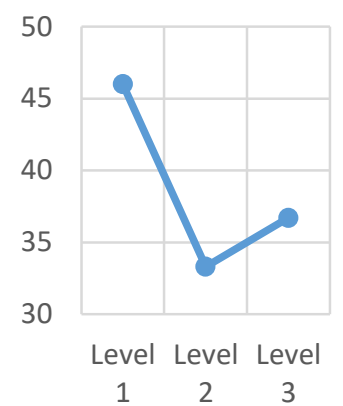

C

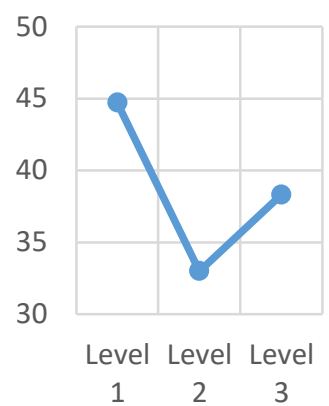

D

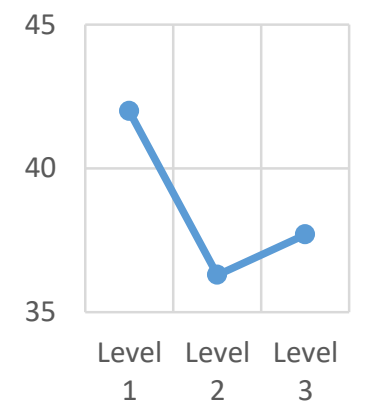

Figure 5: Major effect for the 7 - day compressive strength of geopolymer concrete

Table 12: Response value by Taguchi method for 28 - day compressive strength

\begin{tabular}{lllll}
\hline Level/Factors & A & B & C & D \\
\hline 1 & 45.0 & 47.3 & 45.3 & 44.0 \\
2 & 40.3 & 35.0 & 34.0 & 36.7 \\
3 & 34.3 & 37.3 & 40.3 & 39.0 \\
S. Deviation & 4.38 & 5.34 & 4.62 & 3.05 \\
Rank & 3 & 1 & 2 & 4 \\
\hline
\end{tabular}

A

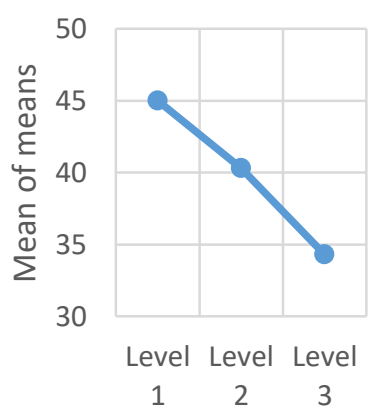

B

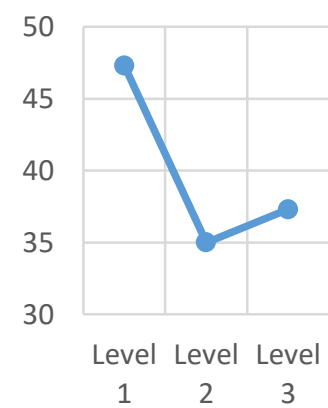

C

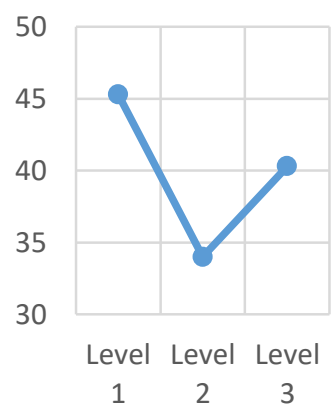

D

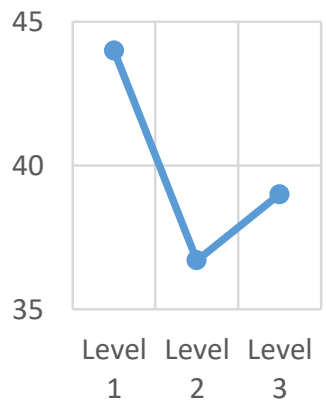

Figure 6: Major effect for the 28 - day compressive strength of geopolymer concrete 


\subsection{Comparative analysis of geopolymer concrete and Portland cement concrete}

The comparative analysis of the 7 and 28 - day's compressive strength pattern of geopolymer and Portland cement concrete is as presented in Figure 7.

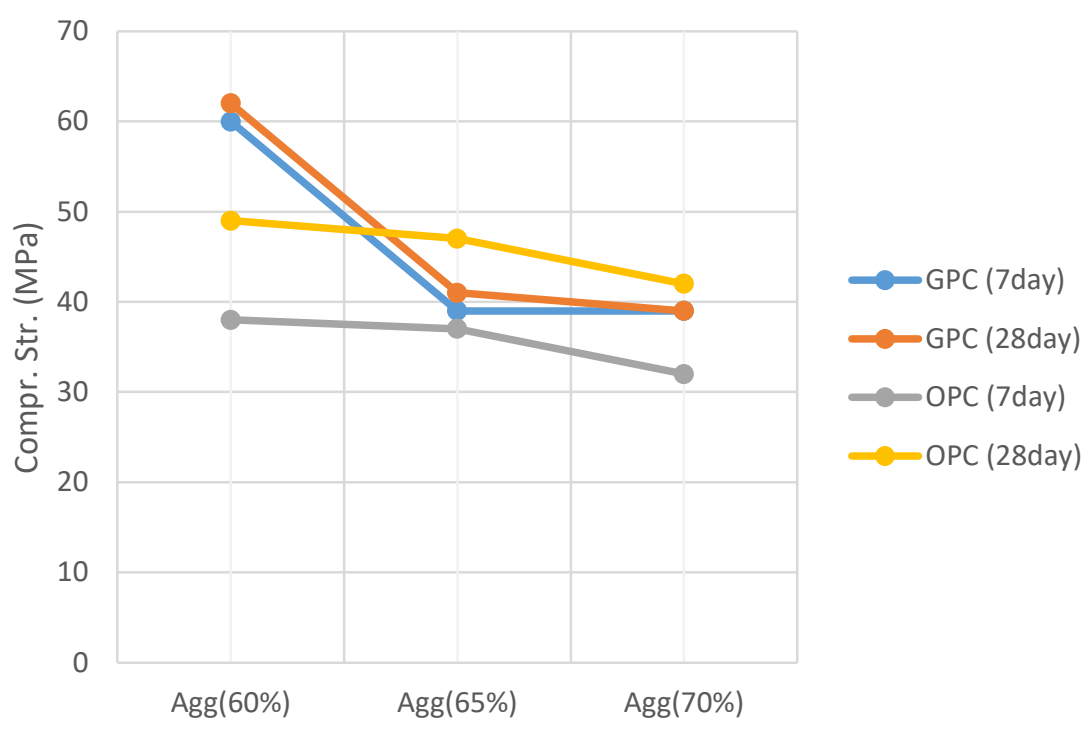

Figure 7: Compressive strength comparison between metakaolin - based geopolymer concrete and Portland cement concrete

From Figure 7 it is clear that the aggregate content in concrete has significant effects on strength development of both concretes however, these effects are quite different in terms of strength development for both type of concrete. While the 7 - day and 28 - day strength of geopolymer concrete are very close and concave in shape as a result of connecting the three aggregate contents, that of Portland cement concrete is wider and convex in shape. This is a pointer to the fact that these two concrete cannot be treated the same and the difference cannot be traced to difference in aggregate content but rather to other factors like the chemistry and difference in chemical composition between the two materials.

\subsection{Conclusions}

In this study, nine mixes based on Taguchi Orthogonal array was used to reduce the number of trial mixes required to achieve a high strength geopolymer concrete under open air curing condition, considering various mix parameters ranging from aggregate content, alkali - binder ratio, sodium silicate - sodium hydroxide ratio and sodium hydroxide molarity. An optimum mix with formulation formula of $2.75 \mathrm{SiO}_{2} * \mathrm{Al}_{2} \mathrm{O}_{3} * 0.55 \mathrm{Na}_{2} \mathrm{O} * 6.8 \mathrm{H}_{2} \mathrm{O}$ was obtained for metakaolin - based geopolymer concrete mix for open air curing. With the compressive strength results obtained and the insights into the effects of the selected mix parameters on the compressive strength of geopolymer concrete as a result of the analysis by Taguchi method, this method was found suitable for optimization of metakaolin - based geopolymer concrete mixtures.

\section{References}

Ahmed Al - dujaili, M. A., Disher Al - hydary, I. A. and Zayer Hassan, Z. (2020). Optimizing the properties of metakaolin - based $(\mathrm{Na}, \mathrm{K})$ - geopolymer using Taguchi design method. International Journal of Engineering, 33(4), pp. $631-638$.

De Side, G. N., Kencanawati, N. N. and Hariyadi (2020). An application of Taguchi experiment design methods on optimization of mortar mixture composition with silica fume as a partial substitution for cement. IOP Conference Series: Earth and Environmental Science, 413(1), pp. 012012.

Fernandez-Jimenez, A., Palomo, A. and Lopez-Hombrados, C. (2006) Engineering properties of alkali-activated fly ash concrete. ACI Materials Journal, 103(2), pp. 106-112. 
Hardjito, D., Wallah, S. E., Sumajouw, D. M. J. and Rangan, B. V. (2004). On the development of fly ash based geopolymer concrete. ACI Materials Journal, 101(6), pp. 467-472.

Ikponmwosa, E., Falade F. and Fapohunda C. (2014). A review and investigation of some properties of foamed aerated concrete. Nigeria Journal of Technology (NIJOTECH), 33(1), pp. 1 - 9.

Montgomery, D. C. (2013). Design and analysis of experiments, John Wiley \& Sons, Inc.

Olivia, M. (2011). Durability related properties of low calcium fly ash based geopolymer concrete. Department of Civil Engineering, Curtin University of Technology. PhD Thesis

Ozbay, E., Oztas, A., Baykasoglu, A. and Ozbebek, H. (2009) Investigating mix proportions of high strength self - compacting concrete by using Taguchi method. Construction and Building Materials, 23(2), pp. 694-702.

Pera, J. (2001). Metakaolin and calcined clays, Cement Concrete Composition, 23

Pouhet, R. (2016). Formulation and durability of metakaolin - based geopolymers. Civil Engineering Universite paul Sabastier - Toulouse III, NNT:2015TOU30085

Shihab, A. M., Abbas, J. M. and Ibrahim, A. M. (2018). Effects of temperature in different initial duration time for soft clay stabilized by fly ash based geopolymer. Civil Engineering Journal, 4(9), pp. $2082-2096$.

Shindunata, van Deventer J. S. J., Lukey, G. C. and Xu, H. (2006) Effect of curing temperature and silicate concentration on fly ash based geopolymerization. Industrial \& Engineering Chemistry Research, 45(10), pp. 3559-3568.

Taguchi, G. and Konishi, S. (1987). Taguchi methods, orthogonal arrays and linear graphs, tools for quality American Supplier Institute. American Supplier Institute, pp. 8-35.

Wu, Z. and Naik, T. R. (2003). Chemically activated blended cements. ACI Materials Journal, 100(5), pp. 434-440. 